\title{
Prevalence of metabolic syndrome in primary health settings in Qatar: a cross sectional study
}

\author{
Mohamed Ahmed Syed*, Ahmed Sameer Al Nuaimi, Abdul Jaleel A. Latif Zainel and Hamda Abdulla A/Qotba
}

\begin{abstract}
Background: In Qatar, prevalence of metabolic components is significantly higher compared to other countries. It is therefore urgent to understand the prevalence of metabolic syndrome (MetS) with the goal of identifying etiologic factors in Qatar. This study was undertaken to estimate the prevalence of MetS, by age, gender and nationality within primary care settings in Qatar. In addition, it determined the independent effects of risk factors on the prevalence of MetS.

Methods: A cross-sectional study design was used. Data for individuals aged $\geq 18$ and who visited a publicly funded primary health centre in Qatar during 2017 were extracted from electronic medical records and analysed.

Results: The findings showed that the prevalence of individual MetS components ranged between 48.5-60.3\%. Overall prevalence of MetS was $48.8 \%(N=62,492)$ in the study population. Prevalence of MetS increased with age. $50.3 \%$ of the population within the 40-49 year age group had MetS. In this age band, individuals were 5.1 times more likely of having MetS compared to the 18-29 year age group. MetS was slightly more prevalent in men (56 $.7 \%)$ compared to women (42.5\%). However, men were 1.33 times more likely of having MetS compared to women. The prevalence of MetS ranged between 20.6 - 60\% across nationalities. It was most prevalent in Southern Asians (60\%), followed by Northern Africans (50.7\%) and Western Asians (excluding Qatar) (46.8\%). Prevalence of MetS in Qataris was 43\%. Southern Asians, Northern African and Western Asians were 1.73, 1.38 and 1.17 more likely to have MetS compared to Qataris.

Conclusions: The study provides essential epidemiological information required by decision makers. Although not nationally representative, this study is suggestive of a higher prevalence of MetS among a younger population, men and in Southern Asian, Northern African and Western Asian nationalities. Prevention, treatment and control of MetS is a public health problem in Qatar. More studies are needed to establish which public health interventions are likely to be effective in Qatar.
\end{abstract}

Keywords: Metabolic syndrome, Primary care, Qatar, Obesity, Hypertension, Dyslipidaemia diabetes, Prevalence

* Correspondence: ahmed.sy3d@gmail.com

Directorate of Clinical Affairs, Primary Health Care Corporation, P.O. Box

26555, Doha, Qatar

C C The Author(s). 2020 Open Access This article is licensed under a Creative Commons Attribution 4.0 International License, which permits use, sharing, adaptation, distribution and reproduction in any medium or format, as long as you give appropriate credit to the original author(s) and the source, provide a link to the Creative Commons licence, and indicate if changes were made. The images or other third party material in this article are included in the article's Creative Commons licence, unless indicated otherwise in a credit line to the material. If material is not included in the article's Creative Commons licence and your intended use is not permitted by statutory regulation or exceeds the permitted use, you will need to obtain permission directly from the copyright holder. To view a copy of this licence, visit http://creativecommons.org/licenses/by/4.0/ The Creative Commons Public Domain Dedication waiver (http://creativecommons.org/publicdomain/zero/1.0/) applies to the data made available in this article, unless otherwise stated in a credit line to the data. 


\section{Background}

Metabolic syndrome (MetS) is a complex asymptomatic, pathophysiological state [1]. It is defined by the cooccurrence of insulin resistance, obesity, atherogenic dyslipidemia and hypertension [2]. It is generally agreed that having three or more of these aetiologically linked cardiometabolic risk factors increases the risk of developing multiple chronic diseases (such as cardiovascular disease, type 2 diabetes (T2DM), arthritis, chronic kidney disease, schizophrenia, several types of cancer and of early death $[1-14]$.

During the past several decades, the prevalence of MetS has markedly increased worldwide [15]. It is estimated that $25 \%$ of the world's population has MetS [16] although this estimate varies widely due to the age, ethnicity, and gender of the population studied [17]. MetS is associated with high socioeconomic cost [18]. Behavioral and environmental changes, such as adoption of a westernized diet and sedentary lifestyle following the socioeconomic rise in developing countries, are thought to be the main reasons for this pandemic of metabolic syndrome [19]. Qatar, a peninsular Arab country with a backed by the world's third-largest natural gas and oil reserves, has experienced a rapid socioeconomic growth during the last two decades and the income of its residents has been rising.

In Qatar, prevalence of MetS components is significantly higher compared to other countries. It is estimated $23 \%$ of Qataris and $18.3 \%$ non-Qataris have T2DM [20]. Prevalence of obesity rates in Qatar ranks fifth globally and is estimated to be $44 \%$ in men and $54.7 \%$ in women [21]. Similarly, in Qatar the prevalence of hypertension and raised total cholesterol was reported as 32.9 and $21.9 \%$ respectively. Based on existing trends, substantial increases in the proportion of the population is likely to meet MetS criteria thus at an increased risk for more serious chronic conditions and premature death.

Studies have previously been conducted to establish prevalence and determinants of metabolic syndrome provide valuable information, however, they include Qataris only [22]. Given expatriates account for $88 \%$ of Qatar's population [23], more recent studies which also include them are required. It is therefore urgent to understand the MetS prevalence with the goal of identifying etiologic factors in Qatar. Early identification of MetS components could lead to targeted public health interventions to prevent the development of the syndrome, and thus chronic disease risk in later life. This study was undertaken to estimate the prevalence of MetS, by age, gender and nationality within primary care settings in Qatar. In addition, it determined the independent effects of risk factors on the prevalence of metabolic syndrome.

\section{Methods}

\section{Study settings}

Qatar has been investing significantly in its healthcare system. This includes a universal publicly funded primary healthcare service delivered by the Primary Health Care Corporation (PHCC). PHCC is the largest primary care provider in the country publicly with 27 health centres (all accredited by Accreditation Canada International and distributed across three geographical regions).

\section{Study population and data collection}

The study population includes both Qataris and nonQataris registered at a PHCC health centre, aged $\geq 18$ and who visited a health centre between 1 January 2017 and 31 December 2017. Demographic and diagnosis data were extracted from the electronic medical records (EMR) for the defined population.

\section{Definitions and data analysis}

A total of 421,283 individuals accessed primary healthcare services in 2017. The National Cholesterol Education Program Adult Treatment Panel III (NCEP ATP III) component definitions was adapted for the study [24] (Supplementary file; Table A) based on the data available in the EMR system. As with NCEP ATP III, MetS is considered present if three or more of the following five criteria are met (or medication was taken to control them).

The proportion of least and most missing data for a MetS component was high blood pressure (3.3\%) and low serum high-density lipoprotein (HDL) (56.4\%) respectively (Supplementary file; Table B). Of these 127, 941 had data available for all five MetS components (Supplementary file; Table C). This data was used for the study.

All data were analysed using the 'Statistical Package for the Social Sciences' statistical software package. Basic descriptive statistics were used to analyse the population components (age, gender and nationality; see supplementary file for classification) and MetS components.

A multiple logistic regression model with the risk of having MetS as the dependent (outcome) variable and age, gender and nationality as predictor (explanatory) variables was developed. Crude age specific and age adjusted prevalence rates for MetS components by nationality were calculated. Age-adjusted prevalence rates were calculated using the World Health Organisation (WHO) World Standard Population (2000-2025) to allow comparisons [25].

\section{Ethical considerations}

The study presented a minimal risk of harm to its subjects, and the data collected for it were anonymised. None of the subjects' personal information was available 
to the research team. Overall, the study was conducted with integrity according to generally accepted ethical principles and was approved by the PHCC's independent ethics committee (PHCC/RS/18/02/003).

\section{Results}

\section{Population components}

MetS component data was available for 127,941 individuals who accessed primary healthcare services in 2017 (Table 1). Individuals in the $40-49$ year age group accounted for approximately $24 \%$ of the population. $55.4 \%$ of the study population was women. $35.8 \%$ of the population was Qatari and 64.2\% non-Qatari. The largest non-Qatari nationalities were represented by Southern Asian (25.2\%), Western Asian (15.2\%) and Northern African (16.7\%) - They accounted for $57.1 \%$ of the total study population.

Table 1 Population components of patients

\begin{tabular}{|c|c|c|}
\hline \multirow[t]{2}{*}{ Population Demographics } & \multicolumn{2}{|c|}{$\begin{array}{l}\text { Population with all } 5 \text { MetS } \\
\text { component data available } \\
\text { (Total population }=127,941 \text { ) }\end{array}$} \\
\hline & $\mathrm{N}$ & $\%$ \\
\hline \multicolumn{3}{|l|}{ Age (years) } \\
\hline $18-29$ & 15,744 & 12.3 \\
\hline $30-39$ & 28,832 & 22.5 \\
\hline $40-49$ & 31,650 & 24.7 \\
\hline $50-59$ & 28,948 & 22.6 \\
\hline $60+$ & 22,767 & 17.8 \\
\hline \multicolumn{3}{|l|}{ Gender } \\
\hline Women & 70,853 & 55.4 \\
\hline Men & 57,088 & 44.6 \\
\hline \multicolumn{3}{|l|}{ Nationality } \\
\hline Qatar & 45,854 & 35.8 \\
\hline Southern Asia & 32,205 & 25.2 \\
\hline Western Asia (excluding Qatar) & 19,431 & 15.2 \\
\hline Northern Africa & 21,397 & 16.7 \\
\hline South-eastern Asia & 5447 & 4.3 \\
\hline Sub-Saharan Africa & 1662 & 1.3 \\
\hline Northern America & 788 & 0.6 \\
\hline Northern Europe & 548 & 0.4 \\
\hline Latin America and the Caribbean & 85 & 0.1 \\
\hline Eastern Europe & 126 & 0.1 \\
\hline Southern Europe & 126 & 0.1 \\
\hline Western Europe & 116 & 0.1 \\
\hline Australasia & 95 & 0.1 \\
\hline Eastern-Central Asia & 59 & 0.0 \\
\hline
\end{tabular}

\section{Prevalence of MetS components}

The overall prevalence of metabolic syndrome was $48.8 \%(\mathrm{~N}=62,492)$ in the study population. The prevalence of individuals MetS components ranged between 48.5-60.3\% (Table 2)

The prevalence of each metabolic syndrome component combination and the prevalence of having one, two, three, four, or five metabolic syndrome component by age and gender are shown in Fig. 1. In younger adults (18-39 years), the most prevalent MetS components were obesity (16.1\%) and low HDL (14.7\%) in combination with another MetS component in women while low HDL (14.7\%) and insulin resistance (13.6\%) in combination with two other MetS component were most prevalent in men. In middle aged adults (40-59 years), insulin resistance $(21.4 \%)$ and obesity $(19 \%)$ in combination with two other MetS components were most prevalent in women while insulin resistance $(25.7 \%)$ and high blood pressure (22.7 5) in combination with two other MetS components were most prevalent in men. In older adults $(60+$ years $)$, insulin resistance and high blood pressure in combination with two other MetS components were most prevalent in women (30.8 and $30 \%$ respectively) and men (32.2 and 31.6\% respectively).

\section{Prevalence of MetS by age, gender and nationality}

Prevalence of MetS increased with age. 50.3\% of the population within the 40-49 year age group had MetS (Table 3). They were 5.1 times more likely of having MetS compared to the 18-29 year age group (Table 4). MetS was slightly more prevalent in men (56.7\%) compared to women (42.5\%). However, men were 1.33 times more likely of having MetS compared to women (Table 4).

The prevalence of MetS ranged between 20.6 - 60\% across nationalities. It was most prevalent in Southern Asians (60\%), followed by Northern Africans (50.7\%) and Western Asians (excluding Qatar) (46.8\%). Prevalence of MetS in Qataris was 43\% (Table 3). Southern Asians, Northern African and Western Asians were 1.73,

Table 2 Prevalence of MetS components in patients for whom all 5 MetS component data was available

\begin{tabular}{llc}
\hline $\begin{array}{l}\text { Metabolic Syndrome components } \\
\text { (Total population = 127,941) }\end{array}$ & $\mathrm{N}$ & $\%$ \\
\hline $\begin{array}{l}\text { Insulin Resistance (Serum Fasting } \\
\text { Glucose }>=100 \mathrm{mg} / \mathrm{dl} \text { or }\end{array}$ & 77,100 & 60.3 \\
HbA1C $>=5.56$ ) or T2DM & & \\
$\begin{array}{l}\text { High Blood Pressure (Systolic or } \\
\text { Diastolic) or hypertensive }\end{array}$ & 67,758 & 53.0 \\
$\begin{array}{l}\text { Obesity (Body Mass Index } \\
>=30 \mathrm{~kg} / \mathrm{m} 2 \text { or central obesity) }\end{array}$ & 63,315 & 49.5 \\
$\begin{array}{l}\text { Low serum HDL (<1.04 mmol/L } \\
\text { in male and < 1.3 mm in female) }\end{array}$ & 62,042 & 48.5 \\
$\begin{array}{l}\text { Metabolic syndrome (at least } \mathbf{3} \\
\text { components present) }\end{array}$ & $\mathbf{6 2 , 4 9 6}$ & $\mathbf{4 8 . 8}$
\end{tabular}



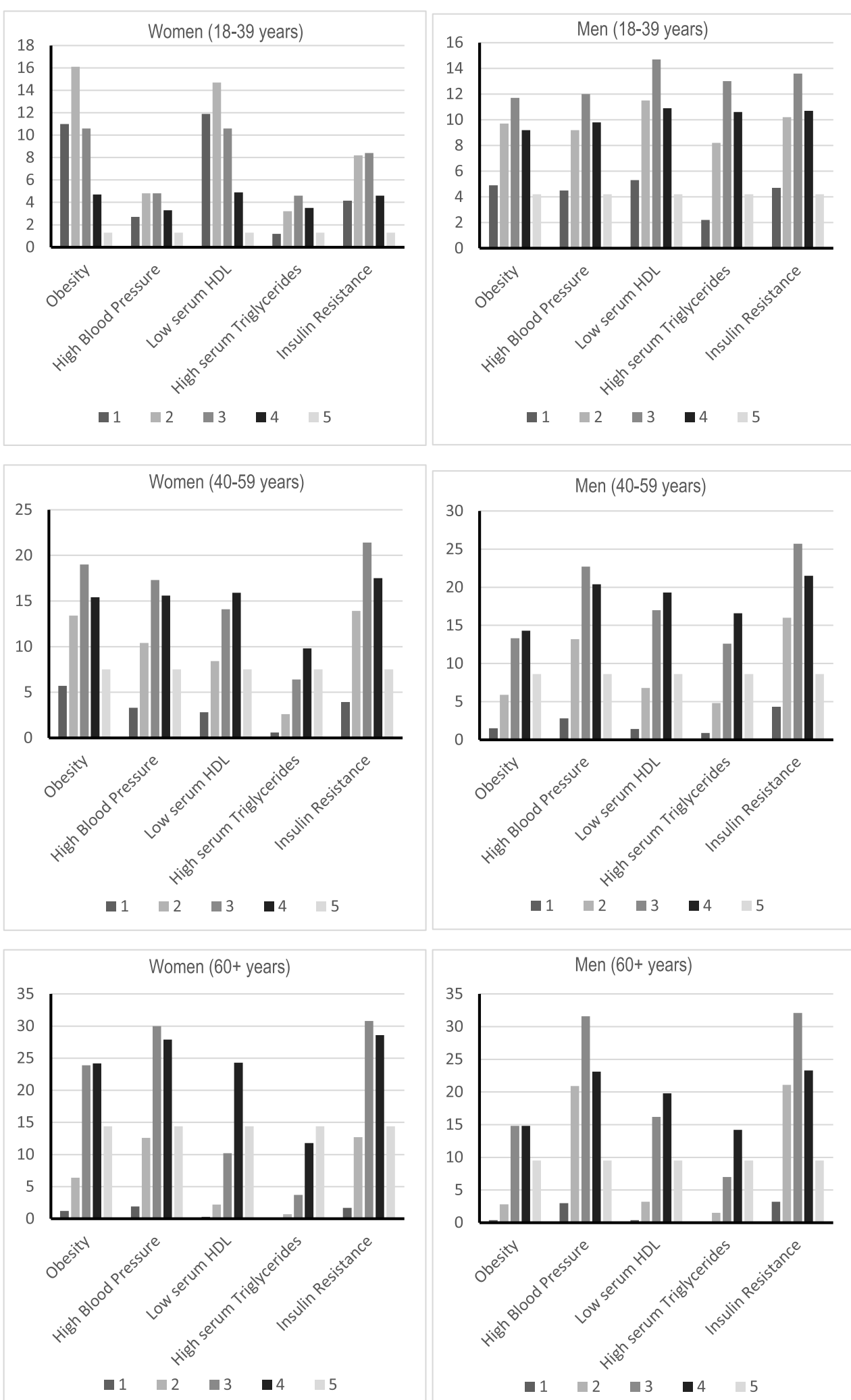

Fig. 1 Prevalence of having one, two, three, four, or five metabolic syndrome component by age and gender 
Table 3 Population components of patients attending publicly funded primary health centers in 2017 with all five MetS component data available

\begin{tabular}{|c|c|c|}
\hline \multirow[t]{2}{*}{ Population Demographics } & \multicolumn{2}{|c|}{$\begin{array}{l}\text { Prevalence of MetS } \\
\text { (Total population }=127,941)\end{array}$} \\
\hline & $\mathrm{N}$ & $\%$ \\
\hline \multicolumn{3}{|l|}{ Age (years) } \\
\hline $18-29$ & 2349 & 14.9 \\
\hline $30-39$ & 9362 & 32.5 \\
\hline $40-49$ & 15,906 & 50.3 \\
\hline $50-59$ & 18,592 & 64.2 \\
\hline $60+$ & 16,287 & 71.5 \\
\hline \multicolumn{3}{|l|}{ Gender } \\
\hline Women & 30,145 & 42.5 \\
\hline Men & 32,351 & 56.7 \\
\hline \multicolumn{3}{|l|}{ Nationality } \\
\hline Southern Asia & 19,310 & 60 \\
\hline Northern Africa & 10,853 & 50.7 \\
\hline Western Asia (excluding Qatar) & 9090 & 46.8 \\
\hline Australasia & 41 & 43.2 \\
\hline Qatar & 19,707 & 43 \\
\hline Northern America & 333 & 42.3 \\
\hline South-eastern Asia & 2204 & 40.5 \\
\hline Northern Europe & 210 & 38.3 \\
\hline Sub-Saharan Africa & 600 & 36.1 \\
\hline Latin America and the Caribbean & 30 & 35.3 \\
\hline Eastern-Central Asia & 20 & 33.9 \\
\hline Eastern Europe & 37 & 29.4 \\
\hline Western Europe & 34 & 29.3 \\
\hline Southern Europe & 26 & 20.6 \\
\hline
\end{tabular}

1.38 and 1.17 more likely to have MetS compared to Qataris (Table 4).

Overall age adjusted MetS prevalence across nationalities was 421/1000 (see supplementary file for MetS prevalence across nationalities). The highest age adjusted rates were 507/1000, 450/1000 and 409/1000 seen in Southern Asians, Northern African and Western Asians (excluding Qatar) respectively. The lowest age adjusted rate was 181/1000 in Southern Europeans. Southern Asians have an age adjusted prevalence are 2.8 times higher than Southern Europeans.

\section{Discussion}

The prevalence of metabolic syndrome (MetS) is on the rise worldwide [26]. This study is potentially the first comprehensive study describing the prevalence of MetS which includes both Qatari and non-Qatari populations in publicly funded primary care settings in Qatar. The study found prevalence of MetS was $48.8 \%$. It also found
Table 4 A multiple logistic regression model with the risk of having metabolic syndrome and age, gender and nationality as predictors

\begin{tabular}{lll}
\hline & Adjusted OR & $P$ \\
\hline Age (years) & & \\
30-39 compared to 18-29 & 2.45 & $<0.001$ \\
40-49 years old compared to 18-29 & 5.10 & $<0.001$ \\
50-59 years old compared to 18-29 & 9.12 & $<0.001$ \\
60+ years old compared to 18-29 & 13.11 & $<0.001$ \\
Gender & & \\
Men compared to women & 1.33 & $<0.001$ \\
Nationality & & \\
Northern Africa compared to Qatari & 1.38 & $<0.001$ \\
Sub-Saharan Africa compared to Qatari & 0.81 & $<0.001$ \\
Latin America and the Caribbean & 0.66 & $0.08[\mathrm{NS}]$ \\
compared to Qatari & & $<0.001$ \\
Northern America compared to Qatari & 0.67 & $0.13[\mathrm{NS}]$ \\
Eastern-Central Asia compared to Qatari & 0.64 & 0.018 \\
South-eastern Asia compared to Qatari & 0.93 & $<0.001$ \\
Southern Asia compared to Qatari & 1.73 & $<0.001$ \\
Western Asia (excluding Qatar) & 1.17 & $<0.0001$ \\
compared to Qatari & & 0.002 \\
Eastern Europe compared to Qatari & 0.52 & 0.001 \\
Northern Europe compared to Qatari & 0.68 & 0.31 \\
Southern Europe compared to Qatari & 0.31 \\
Western Europe compared to Qatari & 0.44 & \\
Australasia compared to Qatari & 0.63 & \\
\hline
\end{tabular}

that over $50 \%$ of the study population had a prevalence of insulin resistance or diagnosis of T2DM. A metaanalysis reported a pooled estimate prevalence of MetS in the Middle East as 25\% [27]. This highlights the significant burden of MetS in the country.

This study, as in all epidemiologic studies, found the prevalence of MetS to increase with age [28]. This is not surprising since there are many commonalities in biochemical changes of aging process and metabolic syndrome/diabetes [28]. However it is worth noting that the prevalence in younger age groups was much higher compared to that reported in other studies. A European study reported a prevalence of approximately 10, 20 and $38 \%$ in $19-39,40-49$ and $60-78$ year age ranges respectively [29] while a prevalence of $23,50.3 \%$ and $71.5 \%$ was found in this study. The onset of MetS in the Qatari population is approximately twice as early compared to European populations. These findings suggests a need for efforts to increase prevention strategies early, ideally when any one of the MetS components manifests and before development of all three required for the formal definition of metabolic syndrome. 
When comparing prevalence of MetS by gender, men (56.7\%) had a higher prevalence compared to women (42.5\%) in this study. MetS was 1.33 times more prevalent in men compared to women. These findings are in line with a study that reported on the prevalence of noncommunicable diseases (NCDs) in primary care settings in Qatar. NCDs, which are outcomes of MetS components, were more prevalent in men compared to women [20]. However in the European population, MetS was more prevalent in women $(32.1 \%)$ compared to men (19.9\%) [29]. Similarly, a systematic review reported a higher prevalence of MetS in women (32.1 to 42.7\%) compared to men (20.7 to $37.2 \%$ ) in Gulf Cooperative Council countries (Bahrain, Kuwait, Oman, Qatar, Saudi Arabia and the United Arab Emirates) [30].

The current study found a higher prevalence rate of $43 \%$ (373/1000) amongst Qataris compared to previous studies $(26.5-33.7 \%)$ [22, 31]. While Southern Asian (60\%, 507/1000), Northern African (50.7\%, 450/ 1000) and Western Asians (46.8\%, 409/1000) had the highest prevalence. Previous studies have not reported prevalence by nationality. It is known that prevalence of MetS varies by ethnicity [32] and given the diversity of the population in Qatar, the study provides essential information in this aspect, which was not available previously.

Prevention of the development of the first MetS component may have significant public health benefits as the presence of one component is predictive of the development of MetS [33]. While, public health strategies that are well known to be important for chronic disease prevention in general can substantially reduce the prevalence of metabolic syndrome [32]. The biggest challenges are identifying individuals with the greatest need for intervention due to their elevated risk for future disease and the population groups associated with the occurrence of MetS. The information reported in the study fill the gap in knowledge and is essential for the success of primary preventive measures of MetS in Qatar. Studies are needed to be establish which public health interventions are most effective in the population groups associated with high risk and occurrence of MetS.

The study has a number of strengths and limitations. Strengths include an up-to-date prevalence of MetS in primary care in Qatar. This provides a baseline for future longitudinal studies to monitor MetS and risk factors as well as in health planning and future strategies. The limitations are as follows: First, this was a crosssectional study and provides a snapshot of the burden at a particular moment in time. Second, the study included only patients who were $\geq 18$ years and those who attended a PHCC health centres in 2017; therefore, it is not nationally representative.

\section{Conclusions}

The study provides essential epidemiological information required by decision makers. Although not nationally representative, this study is suggestive of a higher prevalence of MetS among a younger population, men and in Southern Asian, Northern African and Western Asian nationalities. Prevention, treatment and control of MetS is a public health problem in Qatar. More studies are needed to establish which public health interventions are likely to be effective in Qatar.

\section{Supplementary information}

Supplementary information accompanies this paper at https://doi.org/10. 1186/s12889-020-08609-5.

\section{Additional file 1.}

\section{Abbreviations}

MetS: Metabolic Syndrome; T2DM: Type 2 Diabetes; PHCC: Primary Health Care Corporation; EMR: Electronic Medical Records; NCEP ATP III: National Cholesterol Education Program Adult Treatment Panel III; HDL: High-density lipoprotein; WHO: World Health Organisation

\section{Acknowledgements}

None.

Patient consent and confidentiality Not applicable.

\section{Authors' contributions}

MAS designed the study. ASAN undertook data extraction and analysis. MAS prepared the first draft of the manuscript. All authors read and approved the final version of the manuscript.

\section{Funding}

Not applicable.

\section{Availability of data and materials}

All data generated or analysed during this study are included in this published article and its supplementary information files.

\section{Ethics approval and consent to participate}

The study was conducted with integrity according to generally accepted ethical principles and was approved by the PHCC's independent ethics committee (PHCC/RS/18/02/003). Informed consent was waived due to the retrospective nature of the study.

Consent for publication

Not applicable.

\section{Competing interests}

None.

Received: 22 July 2019 Accepted: 29 March 2020

Published online: 03 May 2020

\section{References}

1. Nolan PB, Carrick-Ranson G, Stinear JW, Reading SA, Dalleck LC. Prevalence of metabolic syndrome and metabolic syndrome components in young adults: A pooled analysis. Prev Med Rep. 2017;7:211-5.

2. Huang PL. A comprehensive definition for metabolic syndrome. Dis Model Mech. 2009;2(5-6):231-7.

3. Mottillo S, Filion KB, Genest J, Joseph L, Pilote L, Poirier P, et al. The metabolic syndrome and cardiovascular risk: a systematic review and metaanalysis. J Am Coll Cardiol. 2010;56(14):1113-32. 
4. Bjørge $\mathrm{T}$, Lukanova A, Jonsson $\mathrm{H}$, Tretli S, Ulmer H, Manjer J, et al. Metabolic syndrome and breast cancer in the me-can (metabolic syndrome and cancer) project. Cancer Epidemiol Biomark Prev. 2010;19(7):1737-45.

5. Borena W, Strohmaier S, Lukanova A, Bjørge T, Lindkvist B, Hallmans G, et al. Metabolic risk factors and primary liver cancer in a prospective study of 578,700 adults. Int J Cancer. 2012;131(1):193-200.

6. Borena W, Edlinger M, Bjørge T, Häggström C, Lindkvist B, Nagel G, Engeland A, Stocks T, Strohmaier S, Manjer J, Selmer R, Tretli S, Concin H, Hallmans $G$, Jonsson $H$, Stattin $P$, Ulmer $H$. A prospective study on metabolic risk factors and gallbladder cancer in the metabolic syndrome and cancer (Me-Can) collaborative study. PloS one. 2014;9(2):e89368.

7. Lindkvist B, Johansen D, Stocks T, Concin H, Bjørge T, Almquist M, et al. Metabolic risk factors for esophageal squamous cell carcinoma and adenocarcinoma: a prospective study of 580,000 subjects within the me-can project. BMC Cancer. 2014;14(1):103.

8. Stocks T, Bjørge T, Ulmer H, Manjer J, Häggström C, Nagel G, et al. Metabolic risk score and cancer risk: pooled analysis of seven cohorts. Int $J$ Epidemiol. 2015;44(4):1353-63.

9. Ulmer H, Bjørge T, Concin H, Lukanova A, Manjer J, Hallmans G, et al. Metabolic risk factors and cervical cancer in the metabolic syndrome and cancer project (me-can). Gynecol Oncol. 2012;125(2):330-5.

10. Nagel G, Stocks T, Späth D, Hjartåkerr A, Lindkvist B, Hallmans G, et al. Metabolic factors and blood cancers among 578,000 adults in the metabolic syndrome and cancer project (me-can). Ann Hematol. 2012; 91(10):1519-31.

11. Almquist $M$, Johansen $D$, Björge $T$, Ulmer H, Lindkvist B, Stocks $T$, et al. Metabolic factors and risk of thyroid cancer in the metabolic syndrome and Cancer project (me-can). Cancer Causes Control. 2011;22(5):743-51.

12. Johansen $D$, Stocks $T$, Jonsson $H$, Lindkvist B, Björge T, Concin $H$, et al. Metabolic factors and the risk of pancreatic cancer: a prospective analysis of almost 580,000 men and women in the metabolic syndrome and Cancer project. Cancer Epidemiol Biomark Prev. 2010;19(9):2307-17.

13. Ford ES. Risks for all-cause mortality, cardiovascular disease, and diabetes associated with the metabolic syndrome: a summary of the evidence. Diabetes Care. 2005;28(7):1769-78.

14. Wu SH, Liu Z, Ho SC. Metabolic syndrome and all-cause mortality: a metaanalysis of prospective cohort studies. Eur J Epidemiol. 2010;25(6):375-84.

15. Borch-Johnsen K. The metabolic syndrome in a global perspective. The public health impact—secondary publication. Dan Med Bull. 2007:54:157-9.

16. O'Neill S, O'Driscoll L. Metabolic syndrome: a closer look at the growing epidemic and its associated pathologies. Obes Rev. 2015;16(1):1-12.

17. Kaur J. A comprehensive review on metabolic syndrome. Cardiol Res Pract. 2014;2014:1-21

18. Kassi E, Pervanidou P, Kaltsas G, Chrousos G. Metabolic syndrome: definitions and controversies. BMC Med. 2011 May 5;9:48

19. Pitsavos C, Panagiotakos D, Weinem M, Stefanadis C. Diet, exercise and the metabolic syndrome. Rev Diabet Stud. 2006;3:118-26.

20. Syed MA, Alnuaimi AS, Zainel AJ, et al. Prevalence of non-communicable diseases by age, gender and nationality in publicly funded primary care settings in Qatar. BMJ Nutr Prev Health. 2019; bmjnph-2018-000014. https:// doi.org/10.1136/bmjnph-2018-000014.

21. $\mathrm{Ng} \mathrm{M}$, et al. Global, regional, and national prevalence of overweight and obesity in children and adults during 1980-2013: a systematic analysis for the Global Burden of Disease Study 2013. Lancet (London, England). 2014; 384(9945):766-81. https://doi.org/10.1016/S0140-6736(14)60460-8.

22. Al-Thani MH, Al-Thani AAM, Cheema S, et al. Prevalence and determinants of metabolic syndrome in Qatar: results from a national health survey. BMJ Open. 2016;6:e009514

23. Priya Dsouza Communications. Population of Qatar by nationality - 2017 report, 2017. Available: http://priyadsouza.com/population-ofqatar-bynationality-in-2017/. Accessed 1 Oct 2018.

24. Grundy SM, Cleeman Jl, Daniels SR, Donato KA, Eckel RH, Franklin BA, Gordon DJ, Krauss RM, Savage PJ, Smith SC Jr, et al. Diagnosis and management of the metabolic syndrome: an American Heart Association/ National Heart, lung and blood institute scientific statement. Circulation. 2005;112:2735-52.

25. Ahmad O, Boschi-Pinto C, Lopez AD, et al. Age standardization of rates: a new who standard. Geneva: World Health Organization; 2001.

26. Osei-Yeboah J, Owiredu WK, Norgbe GK, Yao Lokpo S, Gyamfi J, Alote Allotey E, Asumbasiya Aduko R, Noagbe M, Attah FA. The prevalence of metabolic syndrome and its components among people with type 2 diabetes in the Ho Municipality, Ghana: a Cross-Sectional Study. Int J Chronic Dis. 2017;2017:8765804.

27. Ansarimoghaddam A, Adineh HA, Zareban I, Iranpour S, Hossein Zadeh A, Kh F. Prevalence of metabolic syndrome in Middle-East countries: Meta-analysis of cross-sectional studies. Diabetes Metab Syndr. 2018;12(2):195-201.

28. Stout MB, Justice JN, Nicklas BJ, et al. Physiological aging: links among adipose tissue dysfunction, diabetes and frailty. Physiology. 2017;32(1):9-19.

29. Vishram JKK, Borglykke A, Andreasen AH, Jeppesen J, Ibsen $H$, Jørgensen $T$, et al. Impact of Age and Gender on the Prevalence and Prognostic Importance of the Metabolic Syndrome and Its Components in Europeans. The MORGAM Prospective Cohort Project. PLoS ONE. 2014;9(9):e107294.

30. Mabry RM, Reeves MM, Eakin EG, Owen N. Gender differences in prevalence of the metabolic syndrome in gulf cooperation council countries: a systematic review. Diabet Med. 2010;27(5):593-7.

31. Bener A, Zirie M, Musallam M, Khader YS, Al-Hamaq AO. Prevalence of metabolic syndrome according to adult treatment panel III and international diabetes federation criteria: a population-based study. Metab Syndr Relat Disord. 2009;7(3):221-9.

32. Moore JX, Chaudhary N, Akinyemiju T. Metabolic syndrome prevalence by race/ethnicity and sex in the United States, National Health and nutrition examination survey, 1988-2012. Prev Chronic Dis. 2017:14:E24.

33. Cheung BMY, Wat NMS, Tam S. Components of the metabolic syndrome predictive of its development: a 6-year longitudinal study in Hong Kong Chinese. Clin Endocrinol. 2008;68(5):730-7.

\section{Publisher's Note}

Springer Nature remains neutral with regard to jurisdictional claims in published maps and institutional affiliations.
Ready to submit your research? Choose BMC and benefit from:

- fast, convenient online submission

- thorough peer review by experienced researchers in your field

- rapid publication on acceptance

- support for research data, including large and complex data types

- gold Open Access which fosters wider collaboration and increased citations

- maximum visibility for your research: over $100 \mathrm{M}$ website views per year

At $\mathrm{BMC}$, research is always in progress.

Learn more biomedcentral.com/submissions 